University of Nebraska - Lincoln

DigitalCommons@University of Nebraska - Lincoln

$1-2001$

\title{
The Impact of Unmediated Document Delivery on Faculty Use of Traditional Interlibrary Loan at Wichita State University
}

Kathy A. Downes

Wichita State University, downes@twsuvm.uc.twsu.edu

Ted Naylor

University of Nebraska - Lincoln, tnaylor@unlnotes.unl.edu

Follow this and additional works at: https://digitalcommons.unl.edu/libraryscience

Part of the Library and Information Science Commons

Downes, Kathy A. and Naylor, Ted, "The Impact of Unmediated Document Delivery on Faculty Use of Traditional Interlibrary Loan at Wichita State University" (2001). Faculty Publications, UNL Libraries. 176. https://digitalcommons.unl.edu/libraryscience/176

This Article is brought to you for free and open access by the Libraries at University of Nebraska-Lincoln at DigitalCommons@University of Nebraska - Lincoln. It has been accepted for inclusion in Faculty Publications, UNL Libraries by an authorized administrator of DigitalCommons@University of Nebraska - Lincoln. 


\title{
The Impact of Unmediated Document Delivery on Faculty Use of Traditional Interlibrary Loan at Wichita State University
}

\author{
Kathy A. Downes \\ Ted E. Naylor
}

\begin{abstract}
In these times of growing journal prices and shrinking budgets, alternative methods of information access are a necessity. Document delivery services have become an important alternative to providing information access beyond traditional interlibrary loan services. This article analyzes the effect the "unmediated" EbscoDoc document delivery service had on traditional interlibrary loan in a medium sized academic library. Access to the service was provided to faculty members at Wichita State University for a period of approximately two years. Use of the service varied from faculty members who ordered one article to the "super" users who ordered from 100 to 400 documents. This study indicates that while the few "super" users had a strong impact on document delivery, the presence of the EbscoDoc service did not reduce the use of interlibrary loan as the majority of the registered faculty continued to use traditional interlibrary loan. [Article copies available for a fee from The Haworth Document Delivery Service: 1-800-HAWORTH.E-mail address: <getinfo@haworth pressinc.com> Website: <http: :/www HaworthPress.com> (C) 2001 by The Haworth Press, Inc. All rights reserved.]
\end{abstract}

KEYWORDS. EbscoDoc, interlibrary loan, unmediated library loan, Wichita State University

Kathy A. Downes, MSLS, MPA, is Associate Dean for Information Services, Wichita State University (E-mail: downes@twsuvm.uc.twsu.edu). Ted Naylor, MLS, is Interlibrary Loan Librarian, Wichita State University (E-mail: naylor@twsuvm.uc. twsu.edu).

Address correspondence to: Ablah Library, Wichita State University, Box 68, Wichita, KS 67260-0068.

Journal of Interlibrary Loan, Document Delivery \& Information Supply Vol. 12(1) 2001

(C) 2001 by The Haworth Press, Inc. All rights reserved. 


\section{INTRODUCTION}

In these times of growing journal prices and shrinking budgets, alternative methods of information access are a necessity. Many interlibrary loan (ILL) services rely upon commercial document delivery providers to supply at least a portion of patron requested material. Many other libraries also provide access to "semi-mediated" or unmediated patron document delivery programs as alternatives to the purchase of higher priced journals. What impact these new services have on traditional ILL services is a question asked by interlibrary loan librarians and administrators alike. This article is an attempt to answer that question by analyzing the impact an unmediated commercial document delivery service had on the traditional interlibrary loan activities at a medium sized academic library. In the fall of 1996, Wichita State University (WSU) introduced EbscoDoc, an unmediated document delivery service offering access to over 30,000 titles. The service was offered to WSU faculty only. The goal of the EbscoDoc project was to provide faculties with an alternative to onsite access to high priced or low use journals and to help ease the service demands on the WSU ILL staff. The service was unmediated in the sense that articles were ordered by the end user with no restrictions placed upon the number of articles that could be ordered. WSU faculty were registered and trained first in how to use the service, after which they were allowed to search and order articles via the World Wide Web, with the option of delivery by fax, Ariel, or mail.

\section{BACKGROUND}

Wichita State University is situated in south central Kansas in the state's largest metropolitan area. Student enrollment numbers approximately 14,500 students in 61 undergraduate programs, 46 master's programs, and 10 doctoral programs. Full-time faculty members total 463 . WSU is classified by the Carnegie Foundation as a Doctoral II institution. The WSU Ablah Library contains over one million volumes and employs 21 professional librarians and 23 support staff. Interlibrary loan at WSU consists of one professional, two full-time library assistants, one part-time library assistant and approximately 40 student assistant hours per week. The majority of requested material is ordered via the OCLC system and approximately $65 \%$ of all borrowed material is acquired within the state. 
As unmediated document delivery was a new concept for our library, we were interested in learning both if our ILL workloads would be decreased and if the service would be used as a substitute or merely a supplement to traditional ILL services. In searching the literature we found an article by Minna Sellers and Joan Beam of Colorado State University that described the establishment of an Uncover2 service (Sellers, 1995). This article, which mentioned that ILL use did not fall during their study period, gave us insight into user service desires, but did not go into detail about the ILL behavior of its Uncover2 users. Later, we found an article by Carol Kochan and John Elsweiler describing an EbscoDoc experiment at Utah State University (Kochan, 1998). While small in scope, the faculty in this study did compare their perceptions of traditional ILL Versus EbscoDoc, but again the article did not go into detail about patron use of traditional ILL during the EbscoDoc experiment.

\section{INTERLIBRARY LOAN ACTIVITY PRIOR TO THE EbscoDoc SERVICE}

In preparation for the implementation of the EbscoDoc project, we began analyzing ILL statistics from the four years prior to the EbscoDoc project. We planned to use this analysis as a baseline for evaluating the impact that the EbscoDoc project had on traditional ILL. We found that ILL borrowing requests averaged 11,125 requests per year. During this period, WSU graduate students comprised the largest group of ILL users with an average of $48 \%$ of total material requested. WSU faculty was the second highest user group accounting for an average of $29 \%$ of the total requests. Undergraduates and replacement page requests accounted for the remaining material. As the EbscoDoc service was limited to faculty, we next examined faculty ILL use patterns more closely.

The number of WSU faculty users of ILL services, from fiscal year 1993 through fiscal year 1996, averaged 241 per year. This constituted approximately $52 \%$ of the total number of full-time WSU faculty. Faculty members averaged seven ILL copy requests per year. Individual faculty members presented a wide range of ordering patterns with some ordering only one item per year while a small number of "super users" ordered over 100 items per year. During this time period overall faculty ILL borrowing rose $22.5 \%$. The reason for this increase is unknown, but may be attributed to either an increase in research level by various faculty members or the increased availability of research materials. 
The eight academic departments that consistently appeared in the "top ten" group were: Criminal Justice, Biology, Chemistry, History, Modern and Classical Languages, Library (non-ILL), Nursing, and Psychology. Due to the relatively modest number of users per department, our analysis revealed that a department's use ranking could be greatly influenced by high levels of research on the part of one or two faculty members. For example, in one year a faculty member from Health Sciences ordered 116 items that accounted for $68 \%$ of the orders attributed to that department. In another year, two faculty members in the Nursing Department combined to order 207 articles that accounted for $81 \%$ of the items attributed to that department.

We next focused in on the pre-study ILL activities of our study group, the faculty who registered to use EbscoDoc and who remained at WSU throughout the study time period. Our analysis of this group indicated that $17 \%$ had no ILL activity during the four years prior to the beginning of the study. The remaining $83 \%$ averaged seven copy requests per year, matching the average of the total faculty population prior to the start of the study. The top ten requesting departments of this group were: Nursing, Biology, Health Sciences, Modern and Classical Languages, Library (non-ILL), Chemistry, Mathematics, Management, Criminal Justice, and History. (See Table 1.)

Psychology was the single department, on the general list, not appearing as a top department on the study group's list. In examining specific use records for this department, it was noted that one faculty member, who was a heavy user of ILL, did not register for EbscoDoc. This situation again caused us to note how the activity or inactivity on the part of one faculty member could greatly impact a department's use ranking.

\section{THE EbscoDoc PROJECT}

In the spring of 1996 the Library decided to offer the EbscoDoc service because it featured a number of options that would be useful to the WSU faculty. The service had a table of contents component as well as ALERT, a feature which provided current awareness to a large collection of articles and conference proceedings. Faculty members were able to order articles, books, patents, and proceedings or standards directly from a search screen or they had the option to complete an electronic form for citations not located through the EbscoDoc service. One of the best features of the service was its strong coverage in the areas of sci- 
TABLE 1. Use by Registered Faculty: "Top Ten" Departments

\begin{tabular}{|l|l|l|}
\hline $\begin{array}{l}\text { Before EbscoDoc } \\
\text { Study }\end{array}$ & $\begin{array}{l}\text { ILL Use during } \\
\text { Study }\end{array}$ & $\begin{array}{l}\text { EbscoDoc Use During } \\
\text { Study }\end{array}$ \\
\hline & & \\
\hline Nursing & Biology & Industrial Engineering \\
\hline Biology & Health, PE \& Rec. & Biology \\
\hline Health Science & Library (non-ILL) & Mechanical Engineering \\
\hline Modern Class. Lang. & Nursing & Health Science \\
\hline Library (non-ILL) & Criminal Justice & Psychology \\
\hline Chemistry & Health Science & Physicians Assistant \\
\hline Mathematics & $\begin{array}{l}\text { Modern Class. } \\
\text { Lang. }\end{array}$ & Modern Class. Lang. \\
\hline Management & History & Chemistry \\
\hline Criminal Justice & Industrial Engineering & Library (non-ILL) \\
\hline History & Management & Geology \\
\hline
\end{tabular}

ence and engineering that historically have high journal subscription prices.

In the summer of 1996 , a test period of registering and training a small group of faculty for EbscoDoc was completed and by the fall of 1996, the service was officially in operation. By the end of the study, 236 (approximately 51\%) of the WSU faculty had registered and received training for the EbscoDoc service. The service was advertised and administered through the library subject specialists who also registered individual faculty members and served as liaisons for any problems or questions. Training was conducted both by one-on-one sessions and by group sessions and was reinforced with printed handouts. After training, individuals were free to order documents as needed. The service was in operation for a little over two years until the "demise" of EbscoDoc in September 1998. Indications were that Ebsco could not continue to support the cost of their document delivery component. A more extensive description of the origins and design of this project, from a collection development perspective, may be found in the article by Mary Anthes (Anthes, 1999).

For the purpose of this study, we removed those faculty members who left WSU during the duration of the study or who were registered toward the end of the study. This article thus tracks the activities of the remaining 192 faculty members who were at WSU for the entire study. During this time period, the test group initiated 2,242 EbscoDoc re- 
quests for an average of 1,121 requests per year. Eighty-four faculty members or $43 \%$ of the 192 registrants chose to use EbscoDoc. The average annual EbscoDoc use of this group was 13.3 requests per faculty. The academic departments recording the highest annual average use were: Industrial Engineering, Biology, Mechanical Engineering, Health Sciences, Psychology, Physician Assistant, Modern and Classical Languages and Literatures, Chemistry, Geology, and Urban Studies. (See Table 1.) As with ILL, the range of use was great with many faculty members ordering only one or two items while a few users requested over 100 items in one year. Again, due to the relatively modest number of requests and users, strong research activity on the part of one or two faculty members often dramatically affected the ranking of a department's use of EbscoDoc. For example, while nine members of the Biology Department used the service, one faculty member accounted for $74 \%$ of the 493 items ordered during one year, and in Psychology, two of the seven users accounted for $92 \%$ of the use. It is interesting to note that one of the high use Psychology faculty members had previously been a moderately high user of ILL, but used EbscoDoc almost exclusively during the study period. This example indicates a document delivery service has the potential to change the research habits of a faculty member.

\section{INTERLIBRARY LOAN ACTIVITY BY REGISTERED USERS}

We next looked at the interlibrary loan activity of the registered group during the test period. We first looked to see if there had been any shift among the disciplines. We found that eight of the top ten departments from our pre-EbscoDoc ILL statistics-Biology, Library (non-ILL), Nursing, Criminal Justice, Health Science, Modern and Classical Languages, History, and Management-remained top users during the EbscoDoc study and that four of the departments-Biology, Health Science, Modern and Classical Languages, and the Librarywere also ranked in the EbscoDoc top ten. (See Table 1.)

The two departments that slipped from the ILL top ten were Mathematics and Chemistry. Mathematics was still an active department and had actually increased its average annual requests from 46 to 56 requests, but had slipped to 12 in the rankings due to higher levels of activities by other departments. The second department to drop out of the top group, Chemistry, now ranked at 19, did appear in our top department list of EbscoDoc users. We then looked to see if this change in ranking indicated a shift in service preference from ILL to EbscoDoc. 
When we examined the individual use statistics, we discovered that the EbscoDoc use was by three faculty members who had been light users of ILL prior to EbscoDoc, and that four other faculty members, who previously had generated high ILL statistics, were now inactive. These statistics led us to believe that a service preference shift had not occurred in the Chemistry users. We also were surprised to note that Industrial Engineering (IE), a department that had shown light ILL activity preEbscoDoc, now appeared in the top ten lists of both ILL and EbscoDoc. Six faculty members accounted for IE's high ranking with three of these faculty members quadrupling their ILL activity during the EbscoDoc study. All of this analysis of individual users reinforced our belief in the strong impact a few individuals had on departmental rankings.

After looking at departmental statistics, we looked to see if we could determine ILL use patterns among the individual users independent of departmental affiliation. Four general use patterns were identified and are shown in Figure 1:

1. Registered faculty who did not use EbscoDoc after initial training, but continued to use traditional ILL (43\%). We labeled this group the "ILL Only" group.

2. Registered faculty who used both EbscoDoc and traditional ILL $(34 \%)$. This group was labeled the "Both" group.

3. Registered faculty who used only EbscoDoc and not traditional ILL (10\%). The "Only" group.

4. EbscoDoc registered faculty who used neither service (13\%). The "Neither" group.

We examined several factors within each of these groups to determine common characteristics and any major differences. Table 2 illustrates the general breakdown within the groups while Table 3 shows the distribution of use by each group. The past years ILL category consists of ILL copy requests from 1993 to the beginning of EbscoDoc registration in fall 1996. For the purpose of this study, light users were defined as those ordering less than 10 articles during the study period; average users were defined as ordering 10-24 items; moderately high as ordering 25-49 items; high users as 50-99 orders; and "super" users as 100 or more requests during the two year study period.

\section{ILL ONLY GROUP}

The largest group of EbscoDoc registered faculty chose not to use EbscoDoc but continued to use ILL exclusively. From 1993 to 1996, the 
FIGURE 1. Traditional ILL Use vs. EbscoDoc

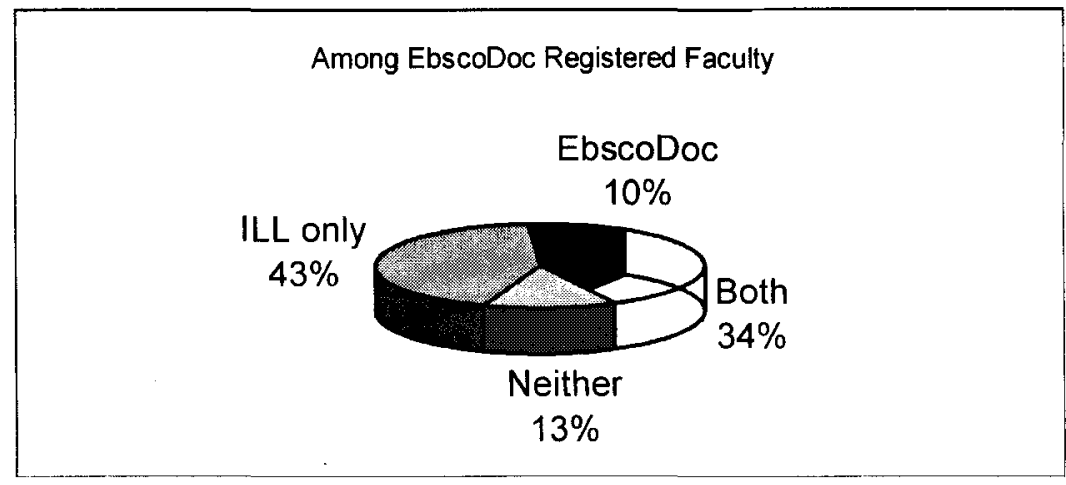

$\begin{array}{lr}\text { ILL only } & 83 \\ \text { EbscoDoc } & 19 \\ \text { Both } & 65 \\ \text { Neither } & 25 \\ \text { Total } & 192\end{array}$

TABLE 2. Summary of Annual Activity of Registered Users

\begin{tabular}{|r|r|r|r|r|r|r|r|}
\hline & \multicolumn{1}{|c|}{$\begin{array}{c}\text { Total } \\
\text { Users }\end{array}$} & $\begin{array}{r}\text { ILL Use } \\
\text { During } \\
\text { Study }\end{array}$ & $\begin{array}{r}\text { ILL Use } \\
\text { Per User }\end{array}$ & $\begin{array}{c}\text { Avg. ILL } \\
\text { Use } \\
\text { Before } \\
\text { Study }\end{array}$ & $\begin{array}{c}\text { EbscoDoc } \\
\text { Use } \\
\text { Uuring } \\
\text { Study }\end{array}$ & $\begin{array}{c}\text { EbscoDoc } \\
\text { Use } \\
\text { Per User }\end{array}$ & $\begin{array}{c}\text { Average } \\
\text { Yrs } \\
\text { WSU }\end{array}$ \\
\hline ILL Only & 83 & 1856 & 11.2 & 6 & & 0 & 12.5 \\
\hline $\begin{array}{r}\text { EbscoDoc } \\
\text { Only }\end{array}$ & 19 & 0 & 0 & 0.6 & 55 & 14.66 & \\
\hline Both & 65 & 1992 & 15.3 & 7.25 & 168 & 12.96 & 10. \\
\hline Neither & 25 & 0 & 0 & 2.39 & & 0.00 & 15. \\
\hline TOTAL & 192 & 3848 & & & 224 & & \\
\hline
\end{tabular}

83 faculty in this group ordered a total of 1,856 items for an average of six interlibrary loan requests annually. During the study period, this group increased its use of traditional interlibrary loan services by $83 \%$ with the group members' mean average rising to 11 traditional interlibrary loan requests per year. Interestingly, the median annual average for this group was only 4.75 articles. The difference in the median and mean averages reflects a pattern seen in the departmental use analysis where a small number of users account for a large percent of the use. Whereas $49 \%$ of the ILL Only group was defined as light users, the top 
TABLE 3. Use Distribution of ILL and EbscoDoc Requests: Total Use During the Study

ILL Use By ILL Only Group

EbscoDoc Use by Ebsco Only Group

\begin{tabular}{|l|r|r|r|r|r|r|r|r|}
\hline 2 Year Total & Users & $\%$ Users & Requests & $\begin{array}{l}\% \\
\text { Requests }\end{array}$ & Users & $\%$ Users & Requests & $\begin{array}{l}\% \\
\text { Requests }\end{array}$ \\
\hline $0-9$ items & 41 & $49.40 \%$ & 174 & $9.38 \%$ & 11 & $57.89 \%$ & 28 & $5.03 \%$ \\
\hline $10-24$ items & 28 & $33.73 \%$ & 430 & $23.17 \%$ & 3 & $15.79 \%$ & 42 & $7.54 \%$ \\
\hline $25-49$ items & 7 & $8.43 \%$ & 223 & $12.02 \%$ & 3 & $15.79 \%$ & 87 & $15.62 \%$ \\
\hline $50-99$ items & 3 & $3.61 \%$ & 215 & $11.58 \%$ & 1 & $5.26 \%$ & 65 & $11.67 \%$ \\
\hline $\begin{array}{l}100-399 \\
\text { items }\end{array}$ & 4 & $4.82 \%$ & 814 & $43.86 \%$ & 1 & $5.26 \%$ & 335 & $60.14 \%$ \\
\hline & & & & & & & & \\
\hline Total Users & 83 & $100 \%$ & 1856 & $100 \%$ & 19 & $100 \%$ & 557 & $100 \%$ \\
\hline
\end{tabular}

ILL By Both Groups

EbscoDoc Use by Both

\begin{tabular}{|l|r|r|r|r|r|r|r|r|}
\hline 2 Year Total & Users & $\%$ Users & Requests & $\begin{array}{l}\text { \% } \\
\text { Requests }\end{array}$ & Users & $\%$ Users & Requests & $\begin{array}{l}\% \\
\text { Requests }\end{array}$ \\
\hline $0-9$ items & 35 & $53.85 \%$ & 157 & $7.88 \%$ & 33 & $50.77 \%$ & 94 & $5.58 \%$ \\
\hline $10-24$ items & 10 & $15.38 \%$ & 172 & $8.63 \%$ & 13 & $20.00 \%$ & 189 & $11.22 \%$ \\
\hline $25-49$ items & 8 & $12.31 \%$ & 286 & $14.36 \%$ & 4 & $6.15 \%$ & 143 & $8.49 \%$ \\
\hline $50-99$ items & 8 & $12.31 \%$ & 488 & $24.50 \%$ & 10 & $15.38 \%$ & 614 & $36.44 \%$ \\
\hline $\begin{array}{l}100-399 \\
\text { items }\end{array}$ & 4 & $6.15 \%$ & 889 & $44.63 \%$ & 5 & $7.69 \%$ & 645 & $38.28 \%$ \\
\hline & & & & & & & & \\
\hline Total Users & 65 & $100 \%$ & 1992 & $100 \%$ & 65 & $100 \%$ & 1685 & $100 \%$ \\
\hline
\end{tabular}

$5 \%$ of this group ordered over 100 items and accounted for $44 \%$ of the group's requests. The average tenure of the ILL Only group at WSU was 12.6 years with $35 \%$ of the faculty members within their first six years, which were the years leading up to tenure.

\section{USERS OF BOTH TRADITIONAL ILL AND EbscoDoc SERVICES}

The second largest group of users, and most interesting, was the 65 faculty members who chose to use both EbscoDoc and traditional ILL. This "Both" group had higher ILL activity levels than the ILL Only group in the years before the EbscoDoc study with the average user requesting seven articles per year. During the study, the median average of 4.5 ILL requests differed little from the ILL Only group; however, 
the annual mean was 15.3 ILL requests, surpassing the ILL Only group by $37 \%$. Similar to the ILL Only group, the top $6 \%$ "super" users accounted for $45 \%$ of the group's ILL requests. In addition to ILL activity, individuals in this group averaged 13 EbscoDoc requests annually during the study period. If the ILL and EbscoDoc requests are combined, the Both group increased its average use of the Library's document delivery services by $233 \%$ during the study period. The average tenure of this group at WSU was 10 years with $36 \%$ within their first six years.

When the specific use patterns of individuals were examined, it was discovered that $57 \%$ of the Both group used ILL more than EbscoDoc, $40 \%$ used EbscoDoc more than ILL, and $3 \%$ used both services equally. We theorized that if EbscoDoc were being used as a substitute for ILL, we would find that the 15 high users of EbscoDoc would be classed as low users of ILL. On the surface, this appeared true as nine of the 15 $(53 \%)$ were classed as high EbscoDoc users/low ILL users. A further examination revealed, however, that eight of the nine users were previously classed as low ILL users during the years prior to the EbscoDoc study. The remaining six high EbscoDoc high users were scattered across various levels of ILL use. We did not believe this data indicated widespread substitution of EbscoDoc for ILL. Interestingly, we found that only four of the $12(33 \%)$ Both group members classed as high ILL users fell into the low EbscoDoc use while six of the high ILL users were either moderate or high users of EbscoDoc. Even more impressive was that fact that, despite having access and using EbscoDoc, $78 \%$ of the individuals in the Both group increased their use of ILL services over their pre-study activities.

\section{REGISTERED BUT DID NOT USE EITHER SERVICE}

The third group, comprised of 26 EbscoDoc registered faculty, did not use either service. This group also had not initiated much ILL activity before the study. ILL statistics reflect the fact that the average user of this group requested 2.4 articles per year during the four-year period prior to the study with a mean of zero for three of those four years. Further analysis showed that one user accounted for $82 \%$ of the total ILL requests made by this group. This lack of use may be due to lower research interests during the study period or from the faculty members' use of non-library supported alternative methods to obtain information. The average tenure of this group at WSU was the oldest of the four groups at nearly 16 years with only $19 \%$ in their first six years. 


\section{EbscoDoc ONLY}

The smallest group was the 19 faculty members who used EbscoDoc exclusively. The group members' mean average was 15 EbscoDoc requests with a median average of 7.5 requests. This EbscoDoc average was $13 \%$ higher than the Both group's but still lower than the Both group's combined level of use. One user was classed as a "super" user accounting for over $60 \%$ of the total requests completed by this group. The majority $(58 \%)$ fell in the low use group. In the years prior to the study, only four members initiated any traditional ILL activity with three of the four being classed as low ILL users. In looking at the individuals, it appeared that by offering the EbscoDoc service, the Library did attract a new group of users. The average tenure of this group at WSU was nine years with over $45 \%$ in their first six years. This group contained the highest percentage of untenured faculty.

\section{SURVEY AND INTERVIEWS}

The EbscoDoc project team conducted a survey after the first year of EbscoDoc service. Of registered users receiving the survey, $32 \%$ responded. Many of the factors affecting use mentioned by Sellers (Sellers, 1995) and Kochan (Kochan, 1998) were mentioned by our faculty. Problems with technology lack of subject coverage, and poor quality of reproductions negatively impacted the use of EbscoDoc, while ease of use and speed promoted use of the service. The direct ordering option from the ALERT service received high approval. One question asked the users to rate the impact of EbscoDoc on their use of traditional interlibrary loan services. The results indicated that $40 \%$ of the respondents were unsure of the impact, followed by $26 \%$ who believed their use of ILL had decreased. In addition, $19 \%$ of the respondents believed EbscoDoc had no impact on their use of ILL, $4 \%$ believed it had increased their use of ILL, and the remaining $11 \%$ reported they did not use ILL services. This was compared to actual use data, which documented that interlibrary loan use actually rose for $55 \%$ of the study group, decreased for $37 \%$ of the group, while the remaining $8 \%$ had no change in activity.

After two years of EbscoDoc use, we decided to conduct in-depth interviews with faculty members whose ILL use was indicative of the major trends we observed. In these interviews, we discovered that faculty who used both services tended to base their choice on what was most 
convenient for them at the time of need and on the availability of materials. One of our interviewees used EbscoDoc as his primary search tool because it offered document delivery. He found that the coverage matched his needs, and he tended to order items as soon as he discovered them. He did not use ILL often because he usually was not aware of what he wanted until he searched EbscoDoc and then it was convenient to immediately order the document. Another faculty member found that EbscoDoc's coverage was not always sufficient. While he usually could find the recent journal articles he needed in EbscoDoc, he tended to order books and older articles through traditional ILL. Still another faculty member based his choice to use EbscoDoc or ILL on where he was when he discovered the source. He found EbscoDoc was more convenient to use when he discovered sources through the ALERT service, but found traditional ILL paper forms more convenient when he discovered a source while browsing in the Library's stacks or while reading an article. Two of our interviewees tended to use traditional Interlibrary Loan when they encountered trouble in completely identifying a source.

\section{CONCLUSIONS}

Through the analysis of the data for this article, we determined there are many factors that influence the choice to use a document delivery service instead of traditional ILL. In his article discussing issues dealing with commercial document delivery services, Randall Marchinko, founder of Dynamic Services, points out that patrons want document delivery services that allow users to identify sources, provide reliable service and in-depth subject coverage, work with in-house systems, and keep them informed of the status of requested material (Marchinko, 1997). EbscoDoc sought to address many of these preferences but still did not fully meet the needs of our entire faculty. Our use data documented that while a few users did choose to use Ebscodoc exclusively, the majority of registered EbscoDoc users continued to use traditional ILL services for all or the majority of their needs. Indeed the majority increased their use of ILL during the time period of the study. We believe the factors that influenced this behavior most likely include problems with new technology, subject coverage that was not sufficient to match information needs, or possibly a high comfort and satisfaction level with the traditional manner of obtaining research material. Many of the users tried EbscoDoc once or twice but then returned to ordering material via ILL. Our data and interviews also pointed out that as imper- 
fect as ILL can be, researchers still valued the convenience of sending all their requests to one place where all the searching, ordering, and problem-solving was handled for them. As previously noted, however, some patrons will use a document delivery service when the subject coverage matches their needs and documents may be ordered at the point of discovery. For these patrons, a document delivery service is preferable to traditional ILL.

Our research also indicated that a small number of active researchers, at least in a medium sized academic library, could have a major impact on both ILL and commercial document delivery use. Unmediated document delivery services have the potential to be costly if the service attracts even a few new users or current ILL users who migrate to become "super" users of the service. In the end, ILL continued to be the choice of the majority of the faculty users at WSU, and for the foreseeable future, we believe this will remain the case.

Until a document delivery service is developed that can profitably offer a service that is easy to use, deep enough in coverage of both serials and monographs, that assists users in completing partially known citations, and that consistently provides high quality documents, traditional interlibrary loan will continue to remain a vital and important service for academic libraries.

\section{REFERENCES}

Anthes, Mary. (1999) "An Experiment in Unmediated Document Delivery: EbscoDoc at Wichita State University." Library Collections, Acquisitions, \& Technical Services, $23(1), 1-13$.

Kochan, Carol A. and John Elsweiler. (1998) "Testing the Feasibility of Unmediated Document Delivery services with EBSCOdoc: The Utah State University Experience." Journal of Interlibrary Loan, Document Delivery \& Information Supply, 9 (1), 67-75.

Marchinko, Randall Wayne. (1997) "Issues in commercial document delivery. (Resource sharing in a changing environment)." Library Trends, 45 (3), 531-550.

Sellers, Minna and Joan Beam. (1995) "Subsidizing Unmediated Document Delivery: Current Models And a Case Study." Journal of Academic Librarianship, 21, 459-466. 